Research note

\title{
What drives the persistence of presenteeism as a managerial value in hotels?: Observations noted during an Irish work-life balance research project
}

\author{
John Cullen*, Andrew McLaughlin
}

Centre for Management Research, Irish Management Institute, Sandyford Road, Dublin 16, Ireland

\begin{abstract}
A research project on work-life balance and Irish hotel managers by McLaughlin and Cullen (Managers and work-life balance: a case of Irish hospitality industry, Irish Management Institute, Dublin) noted high levels of presenteeism amongst focus group participants. This paper analyses the qualitative data obtained during this project with a view to identifying drivers of this finding and discusses possible consequences for hotel managers. Presenteeism is found to be embedded in narratives of managerial identity and in the management culture of the hotel industry. Three core rationales, which present at organisational and environmental levels, are proposed as forces that reinforce presenteeism as a managerial value in hotels.
\end{abstract}

(C) 2004 Elsevier Ltd. All rights reserved.

Keywords: Presenteeism; Hotel managers; Industry culture; Ireland

\section{Presenteeism}

Cooper (1998) defines presenteeism as 'an overwhelming need to put in more hours or, at the very least, appear to be working very long hours.' Lowe (2002) demonstrates how it manifests itself in two distinct employee behaviours: 'First,

\footnotetext{
*Corresponding author. Fax: + 353012955150 .

E-mail address: john.cullen@imi.ie (J. Cullen).
} 
presenteeism can mean putting in excessive work hours as a perverse expression of commitment or a way of coping with nagging job insecurity... . Second, presenteeism also describes employees going to work sick or injured.' Presenteeism creates myriad difficulties for individual workers and organisations. At an individual level, there is strong empirical evidence of the correlation between increase in working hours and serious health problems (Sokejima and Kagamimori, 1998; Kivimaki et al., 2000), family difficulties and life dissatisfaction (Adams et al., 1996 ). At an organisational level, presenteeism has been found to adversely impact employee effectiveness and productivity (Cooper, 1998; Lowe, 2002) and generate costs to the organisation (The Worklife Report; Anonymous, 2002). Cooper (1998) attributes the emergence of presenteeism as a general trend to widespread downsizing during the early 1990s. This led to substantial job insecurity amongst managers who inherited "the "dual status" of being part of a reduced and increasingly insecure core' (Simpson, 1998). The paradox of presenteeism is that it creates a work culture that demands managers to be physically present whilst simultaneously corroding their mental capacity to be productive and perform effectively. Organisations affected by presenteeism become treadmill cultures that exhaust their managers' strengths and skills for no additional gain, and often at a huge loss. Marcus (2001) states:

Like a wave hitting a beachfront and eroding the shoreline... the phenomenon now commonly known as "presenteeism" is slowing and invisibly eroding the effectiveness of the American workforce. Presenteeism signifies that a number of employees, even those with perfect attendance records on the job, are nonetheless working with impairments and disabilities that cause them to perform less effectively. This results in employers' losing up to 32 times as much productivity from presenteeism as from absenteeism.

\section{Irish national culture and Irish hospitality industry culture}

It is often difficult to appraise a national culture that is undergoing a process of fundamentally re-evaluating its identity. In recent decades, Irish national culture has rapidly undergone a fundamental set of transformations that is unrivalled on a global scale in terms of intensity and pace (Peillon, 2002).

Some findings on Irish work culture are briefly presented here with a view to developing a specific picture of how Irish national culture might contribute to the persistance of presenteeism as a managerial value. Hofstede (1980) found that Irish work culture reports low uncertainty avoidance (i.e. Irish managers have a greater willingness to take risks) and high assertiveness or ambitiousness. Ashkanasy et al. (2002) found that along with other countries in the 'Anglo Cluster', Ireland is characterised by individualistic performance orientations and that Irish people view effective leadership as affected by a combination of charismatic inspiration and a participative style. These findings are important because they report cultural expectations and values with regard to management 
activity and these expectations apply to managerial work values in the Irish hospitality sector.

The observations discussed in this paper arose from research that aimed to examine work-life balance practices and policies in the Irish hotel sector, and to develop an understanding of the work-life balance needs of hotel managers.

A series of four focus groups was undertaken with 27 hotel managers across Ireland. Although there were considerable differences in the age profiles of the participants, all had significant experience in the Irish hotel industry. The overall findings of the research project have been published elsewhere (McLaughlin and Cullen, 2003). One key finding of the research was that 'managers consider work-life balance a priority for employees, but managers still persist in working long hours to the extent that a presenteeism management style is widespread'. Presenteeism was identified strongly and repeatedly as a force in the management culture of the Irish Hotel industry. The researchers decided to re-examine the qualitative data obtained in an attempt to uncover possible drivers of presenteeism in the sector.

\section{Presenteeism as a managerial value in hotels}

Despite the recognition of presenteeism as a relatively recent phenomenon amongst managers in general, our research found that it has been part of the industry in Ireland for a much longer time. This is reflected in statements from participants in our focus groups:

The hospitality industry used to be like the priesthood. You joined up and your personal life disappeared. (Hotel Manager, Male).

Many [hotel] owners worked huge hours themselves and have similar expectations of their managers. (Hotel Manager, Male).

There is a perception of the industry that excessive hours are worked. However, it's not demanded of people, but the culture dictates that it happens that way. (Hotel Manager, Female).

Despite there being a greater awareness of the unconstructive nature of managerial presenteeism in hotels, there was strong agreement across the four focus groups that it continued to be widespread in practice. The persistence of presenteeism as a value became evident through the participants personal narratives on the development of their own identities as managers. Two of these narratives are used to exemplify this:

Narrative One:

A participant discussed how his first job, after completing second level education, involved working long hours in a hotel in the Dublin area during the 1980s when employment was scarce. Following a lengthy period when the participant worked every waking hour, a family member, concerned for the participant's wellbeing, contacted the hotel manager to request that he be granted some time off. 
The following day the participant was informed that if he couldn't handle the hours required that he might be better suited to working in another industry.

Narrative Two:

A female owner/manager related how she had been born into the hotel business and had observed her parents running a hotel in a very hands-on fashion for most of her formative years. She worked in hotels at a management level before running and developing her own properties. She reflected that her own children were raised in the hotel environment. She recounted instances when family concerns competed strongly with her working commitments. This latter narrative ended with a very interesting statement: 'When my mother was able to do it in her time, it was a different story.'

These narratives provide explicit examples of how presenteeism becomes a value at an early stage, either through enculturation as a hotel manager or through an early personal life experience, and is then expressed through managerial behaviours. These managerial behaviours transmitted these values to trainees or newly appointed hotel managers. Hofstede (1991) states: 'Values are acquired in one's early youth, mainly in the family and in the neighbourhood, and later at school. By the time a child is 10 years old, most of its basic values have been programmed into its mind. Organisational practices, on the other hand, are learned through socialisation at the workplace, which most people enter as adults, i.e. with the bulk of their values firmly in place. For occupational values the place of socialisation is the school or university, and the time is in between childhood and adulthood.'

Presenteeism as a value and a behaviour appears to be programmed into managers in the hotel industry at a formative stage, be it at a personal, organisational or an occupational level. Despite this, hotel managers are aware of the dangers of presenteeism and many have taken steps to address this issue. Some who had actively taken steps to re-align their work-life balance found that their management skills had improved:

You need to get away or you just get bitter and twisted and don't see the whole picture. (Hotel Manager, Male).

If you're not fit, you're not fit for work (Hotel Manager, Female).

In very general terms, the researchers noted that female participants appeared to be driven to question presenteeism as a managerial value by changes in their family circumstances, while male participants tended to re-evaluate it as a result of concern for their health.

Despite an awareness that presenteeism is a value that does not always result in positive managerial behaviours, it was noticeable that managers persisted in behaving in a way that demonstrated a strong attachment to unnecessarily long working hours. Our re-examination of the qualitative data produced a suggestion that managers attempted to reduce this dissonance by justifying their presenteeism through three core rationales, which presented at organisational and environmental levels. 
The first of these rationales is based on the strong opinion or belief of hotel managers that they have a clear duty to provide emotional support for their staff. Some participants estimated that they spent up to $40 \%$ of their time 'counselling' staff members, despite not being trained to do this. The participants also noted that the issue of work-life balance was growing in importance in the hospitality sector. Ironically, facilitating work-life balance for staff resulted in additional pressures for managers.

It is the managers responsibility to make sure his or her staff's work-life balance needs are being met. (Hotel Manager, Male).

General managers are conditioned to work hard, but have to stop staff members from working excessive hours. (Hotel Manager, Male).

Managers in hotels demonstrate high levels of care and concern for their staff and for their organisations. Participants told stories of abandoning family and personal events and commitments to assist in resolving minor crises that had emerged at an organisational level. This level of 'care' for staff and the organisation may indicate the presence of strong emotional drivers for presentee management cultures.

The second rationale is that hotel managers are highly conscious that they are perceived as the public face of the hotel and that they offer 'brand value' in being continually present.

In this business you're the brand image and if you're not there the brand is diminished. (Hotel Manager, Male).

The wedding would go fine if I wasn't there but the brides mother expects me to be there. (Hotel Manager, Female).

The third rationale communicated by managers is the actual nature of the industry itself, which is simultaneously customer facing and operates $24 \mathrm{~h}$ and 7 days a week. The hotel is a complex organisation in which several distinct operations work synchronously to provide a quality product to its customer. This generates huge challenges for managers.

There is a dog nipping at your heels in hotels, to move on, move on, be successful. (Hotel Manager, Female).

\section{Discussion}

Ashkanasy et al. (2002) finding that Ireland is characterised by individualistic performance orientations and that Irish people view effective leadership as affected by a combination of charismatic inspiration and a participative style appears to be true in the case of hotel managers. Irish hotel managers are highly committed to their operations and several focus group participants recounted incidences of regularly becoming involved in operational work during busy periods and when staff members were unexpectedly absent due to illness or for other reasons. 
Although Cooper (1998) noted that presenteeism emerged as a general trend during widespread downsizing in the 1990s, it appears that this trend may have reinforced, rather than re-established, presenteeism amongst managers in Irish hotels. Presenteeism has been part of the management cultures of Irish hotels for some time. Despite managers being aware of it as a negative force at an individual level, long working hours continue to persist as a work value at the level of organisational culture and at the level of individual identity for managers.

The initial purpose of this research was to gain an appreciation of work-life balance practices in the Irish hotel sector and presenteeism emerged as a key concern in this research. The limitations of this paper are that it is based on qualitative data obtained in a small sample and the findings need to be tested and verified by research using a larger population sample or in-depth ethnographic methodologies.

It is hoped, nevertheless, that this paper will provide a useful 'jumping-off' point into the reasons why presenteeism continues to persist as a work value amongst managers in Irish hotels. More importantly, it is hoped that it might uncover possible solutions to an unconstructive and unhelpful practice that appears to have become embedded in the culture of the Irish hotel industry.

\section{Acknowledgements}

The authors wish to express their gratitude to the Irish Hotel and Catering Institute, particularly Karl Rheinhardt, Chief Executive, for facilitating the research focus groups and to the two anonymous reviewers for their helpful comments on our first submission.

\section{References}

Adams, G.A., King, L.A., King, D.W., 1996. Relationship of job and family involvement, family social support and work-family conflict with job and life satisfaction. Journal of Applied Psychology 81 (4), $411-420$.

Anonymous, 2002. The Worklife Report 14(3) 11.

Ashkanasy, N.M., Trevor Roberts, E., Earnshaw, L., 2002. The Anglo cluster: legacy of the British empire. Journal of World Business 37, 28-39.

Cooper, C.L., 1998. The changing nature of work [1]. Community, Work and Family 1 (3), 313-317.

Hofstede, G., 1980. Culture's Consequences: International Differences in Work-Related Values. Sage, London.

Hofstede, G., 1991. Cultures and Organisations: Software of the Mind. McGraw-Hill Book Company, London.

Kivimaki, M., Vahtera, J., Pentti, J., Ferrie, J.E., 2000. Factors underlying the effect of organisational downsizing on health of employees: longitudindal cohort study. British Medical Journal 320 , 971-975.

Lowe, G., 2002. Here in body, absent in productivity. Canadian HR Reporter 15 (21), 5-6.

Marcus, C.A., 2001. "Presenteeism", A clear and growing problem. Compensation and Benefits Management 17 (1), 56-58.

McLaughlin, A., Cullen, J., 2003. Managers and Work-Life Balance: The Case of the Irish Hospitality Industry. Irish Management Institute, Dublin. 
Peillon, M., 2002. Introduction. In: Corcoran, M.P., Peillon, M. (Eds.), Ireland Unbound: A Turn of the Century Chronicle. Institute of Public Administration, Dublin.

Simpson, R., 1998. Presenteeism, power and organizational change: Long hours as a career barrier and the impact on the working lives of women managers. British Journal of Management 9 (3 (Special Issue)), S37-S50.

Sokejima, S., Kagamimori, S., 1998. Working hours as a risk factor for acute myocardial infarction in Japan: case-control study. British Medical Journal 317, 775-780.

John Cullen, B.A (Hons), M.A., M.L.I.S is Senior Management Researcher at the Centre for Management Research, Irish Management Institute, Dublin, Ireland.

He has held management positions in academic and statutory organisations in Ireland.

He has extensive research experience and has published in scholarly and professional journals in the U.S, U.K and Ireland.

His current research interests include national competitiveness, management labour markets, organisational culture and management development.

Andrew McLaughlin, B.A. (Psychology), M.Sc. (Management), Diploma European Law, Diploma Legal Studies, Certificate in Public Administration, Diploma in German (Goethe Institute), Diploma in French Studies (CMOD), is Director of Training and Development at the Irish Management Institute.

Andrew leads courses on performance management, communication skills, influencing skills, interviewing skills and team building. He is a Master Practitioner of Neuro Linguistic Programming. A Director of the National Management Forum, he has lectured extensively and has held senior public service roles in Ireland and the European Union. He has conducted management development training and consultancy work in Eastern Europe, the Middle-East, Asia and Africa. Andrew has research interests in the area of well-being and work-life balance issues. 